\title{
Financeirização do Meio Ambiente
}

\section{Financialization of the environment}

\author{
Ana Paula Salviatti ${ }^{*}$ \\ [salviattitrabalho@gmail.com]
}

Recibido: 12 de maio de 2016

Aprobado: 28 de dezembro de 2016

DOI: 10.32991/2237-2717.2016v6i2.p311-321

Citação sugerida: Salviatti, Ana P. "Financeirização do meio ambiente." HALAC VI, no. 2 (Diciembre 2016): 311-321.

\begin{abstract}
RESUMO
0 artigo a seguir propõe uma análise sobre a abordagem oferecida pela economia neoliberal para as políticas voltadas para 0 cenário ambiental e o desenvolvimento das nações ajustadas, então entendido como desenvolvimento sustentável. Para tanto, o fio condutor deste trabalho será o desenvolvimento internacional da economia política das últimas décadas, dimensão na qual ocorreram reacomodações na divisão internacional do trabalho. Dentro do proposto, se destaca a maneira pela qual problemática ambiental recebe tratamento semelhante às outras esferas submetidas à lógica do capitalismo, e resultante desta operação o Protocolo de Quioto figura como a solução melhor adaptada às necessidades da reprodução capitalista em pleno regime de acumulação financeirizado.
\end{abstract}

\section{Palavras Chaves}

Divisão Internacional do Trabalho, Protocolo de Quioto e Financeirização.

\section{ABSTRACT}

The following article proposes an analysis of the approach offered by neoliberal economics to policies aimed at environmental setting and the development of nations set, then understood as sustainable development. To do so, the thread of this work will be the development of international political economy of recent decades, in which occurred re-accommodations in the Global Division of Labour. Within what have been proposed, it highlights the way in which environmental issue receives treatment similar to other spheres that had been subjected to the logic of capitalism, and as a result from this operation the Kyoto Protocol stands as the best policy adapted to the needs of capitalist reproduction in the regime of financialized accumulation.

\section{KEYWORDS}

Global Division of Labor, the Kyoto Protocol and Financialization.

Os anos dourados do capitalismo assistiram além do bom desempenho das economias industrializadas, à tentativa dos países terceiro mundistas em articular sua autonomia política e econômica frente as nações do centro dinâmico. Assim, a inauguração do Movimento dos Países não Alinhados, a busca por uma então chamada Terceira Via, e até a institucionalização da Conferência das Nações Unidas sobre o Comércio e Desenvolvimento, a UNCTAD, nos 1970 são resultados das ações desenvolvidas pelos países que aqui agruparemos como economias induzidas e orientadas.

Essa articulação autônoma dos países não passou despercebida. A possibilidade de que se expandisse, com o exemplo da OPEP, uma série de carteis de produtores de matérias primas pelo mundo foi discutido no artigo de Fred Bergsten para a Comissão

\footnotetext{
* Mestre em História Econômica. Doutoranda ēm Desenvolvimento Econômico. Instituto de Economia. Universidade Estadual de Campinas (Uniçamp). Campinas, Brasil.
} 
Trilateral logo no àno de sua criação, em 1973. A Comissão composta por Estados Unidos, Europa Ocidental e Japão se formou com o objetivo destes países de reunirem-se diante da resistência no mercado internacional oferecida pelo Terceiro Mundo, aumentarem o investimento conjunto e o intercâmbio em pesquisa e o desenvolvimento (P\&D).

Em texto intitulado A Ameaça do Terceiro Mundo, ${ }^{1} 1$, Bergsten exorta seus leitores para existência de um enorme risco de que a autonomia dos países ricos em recursos naturais alterasse a forma como os preços destes produtos de imensa importância e participação nas economias industrializadas se apresentassem no mercado internacional; haja vista o exemplo dado pela OPEP. ${ }^{2}$ Indicava que os países Trilaterais precisavam barrar tais articulações, fosse através da indução de um cooperative-behavior entre os países, por meio de retaliações econômico-comerciais, ou até a adoção de medidas mais drásticas não poderiam ser descartadas, as quais, segundo o autor, mesmo não estando em um momento propício perante a opinião pública após anos de guerra com o Vietnã deveriam ser consideradas. Por fim, uma das últimas recomendações feitas versou sobre a necessidade de aumentar o investimento em pesquisa e desenvolvimento entre os países da organização para criação de substitutos sintéticos das matérias primas importadas.

No mesmo ano foi publicado um estudo realizado no MIT (Massachusetts Institute of Technology) sob a encomenda do Clube de Roma ${ }^{3}$, chamado: Os Limites do Crescimento, ou, Relatório Meadows. ${ }^{4} \mathrm{O}$ estudo inovou ao utilizar na elaboração do seu relatório um modelo computacional, no qual foi possível modelar o comportamento de variáveis escolhidas anteriormente pelos pesquisadores. Porém, os critérios utilizados na escolha das variáveis selecionadas para participação nos diversos cenários simulados não foram discutidos quanto a sua natureza temporal, ou a sua conotação político-social, ou mesmo seu impacto na divisão internacional do trabalho. O Relatório Meadows foi um representante ativo do movimento Neomalthusiano, ${ }^{5}$ pois o centro dos problemas apontados quanto degradação do meio ambiente tìnham origem no crescimento populacional dos países terceiro mundistas. Produzido em plena Guerra Fria, o relatório não fez qualquer menção à existência de modelos econômicos e sociais distintos, em Limites do Crescimento, não há modelos econômicos, há apenas economia, não há estruturas sociais, há a apenas a sociedade.

Entre os resultados oferecidos pelo Relatório Meadows foram propostas reorganizações sociais e apontamentos políticos que exerceram grande influência nas discussões políticas internacionais dentro das Nações Unidas, principalmente as voltadas

\footnotetext{
${ }^{1}$ Bergsten, Fred. "The Threat from the Third World, Foreign Policy." Washingtonpost, Newsweek Interactive, LLC 11 (1973): 102-124, acessado em dezembro 02, 2012, DOI: 10.2307/1148041.

${ }^{2}$ No início dos anos 1960, os países produtores de petróleo formaram a Organização dos Países Exportadores de Petróleo, a OPEP. A formação de um cartel de produtores contrariava a estrutura de mercado moldada a partir das demandas dos países industrializados no que se refere à principal matéria-prima (e ao principal recurso não renovável) dentro da indústria capitalista. A formação da OPEP enfrentou diretamente os interesses das transnacionais petrolíferas, então conhecidas como "Sete Irmãs". Para mais: Yergin, D. O petróleo: Uma história mundial de conquistas, poder e dinheiro, trans. Leila Marina, Maria Guimarães, Maria Góes. São Paulo: Paz e Terra, 2012. Kucinski, B. O que são multinacionais São Paulo: Brasiliense, 2009.

${ }^{3}$ Três anos após o reconhecimento internacional da OPEP, foi formado o Clube de Roma, em 1968, com o objetivo manifesto de 'discutir os problemas a serem enfrentados pela humanidade'.

${ }^{4}$ Meadows, Donella. Limites do crescimento: um relatorio para o projeto clube de roma sobre o dilema da humanidade . São Paulo: Perspectiva, 1973.

${ }^{5}$ O Neomalthusianismo surgiu em meados da década de 1960. A corrente aplicava sobre o contexto moderno as concepções Malthusianas surgidas no século XVIII, as quais eram baseadas na existência de um limite na capacidade de produção de alimentos para abastecer a população mundial, consequentemente o aumento populacional levaria ao desabastecimento e ao caos. Os Neomalthusianos se apropriam das teorias de Thomas Malthus na medida em que correlacionam a expansão populacional com a pobreza e a fome, destacadamente existentes nos países do Terceiro Mundo, ou seja, para o neomalthisianismo a caūsà da fome e da pobreza está ligada ao avanço populacional, e não o contrario.
} 
tanto para os países agrupados no então Terceiro Mundo, quanto para as que vieram a ser desenvolvidas para o meio ambiente.

A primeira conferência das Nações Unidas sobre o tema ambiental ocorreu em Estocolmo, novamente no início dos anos 1970. Oficialmente conhecida como Conferência das Nações Unidas sobre Meio Ambiente Humano, em sua declaração final ficaram de fora preocupações com os desdobramentos ecológicos produzidos pela crescente demanda por matérias primas e recursos naturais pelas nações industrializadas, assim como esteve de fora o uso contínuo de combustíveis fósseis feitos largamente por países industrializados, entretanto, em um contexto de retorno das ideias malthusianas, a Conferência proclamou que o crescimento populacional 'coloca continuamente, problemas relativos à preservação do meio ambiente, e devem-se adotar as normas e medidas apropriadas para enfrentar esses problemas, ${ }^{\prime 6}$ referência feita ao crescimento populacional existente no Terceiro Mundo.

Como foi observado, nas seguintes reuniões articuladas pelas Nações Unidas a temática ambiental e as dificuldades enfrentadas pelas nações em seu desenvolvimento foram construídas conjuntamente, partindo de uma premissa bem específica: a degradação se daria em torno da poluição causada pela pobreza, somente após esta precisa especificação é que seriam acrescentadas tanto as contribuições de governos industrializados, quanto às intervenções de empresas transnacionais.

Paralelamente a este quadro, a estrutura política econômica edificada no pós-guerra passou a apresentar sinais de desgaste, entre as décadas de 1960 e 1970. As políticas de origem keynesiana que implicavam em um 'Estado forte', e no caso Europeu, do próprio Welfare State começavam a desestruturar-se, iniciando um longo processo de transição da economia política internacional.

Em 1973, a OPEP impôs o aumento de preços da sua commodity. A elevação dos preços ficou conhecida pelos seus efeitos na economia internacional como 'Choque do Petróleo'. Foram na realidade três choques (1973, 1978 e 1979) e o primeiro choque reverberou negativamente nos países importadores de petróleo de maneiras e graus diferentes. Simultaneamente, os recursos advindos do aumento dos preços do petróleo inundaram os bancos, principalmente da City de Londres e de Nova lorque, criando uma enorme liquidez nos mercados financeiros recém-reabertos.

A inflação dos preços da matriz energética generalizou-se, e somados ao baixo crescimento, gerou a estagflação nos países industrializados, ${ }^{7}$ situação que rapidamente refletiu no comércio internacional. Por meio da inflação no Primeiro Mundo, ocorreu a compressão da demanda renda por produtos importados do Terceiro Mundo, através da perda de trocas para os produtos dos países de capitalismo baseado no setor primário exportador.

Os chamados petrodólares passaram a ser reciclados de diversas maneiras, inclusive sob a forma de créditos baratos para os países de economia mais vulneráveis, as quais

\footnotetext{
${ }^{6}$ ONU. Declaração Da Conferência Das Nações Unidas Sobre O Meio Ambiente Humano - 1972. Declaração de Estocolmo, 1972.

7 'A economia americana apresentou, durante a década dos 70, um reduzido quadro de crescimento, elevada inflação e inusitados níveis de desemprego, se comparado com o desempenho econômico dos anos 60" Presser, Mário Ferreira. "Crise Americana 'supply-Side Economics.'" Revista de Economia Política, 1981: 113.

'A economia norte-americana cai de 40\% da produção mundial, em 1950, para 22\% em 1978; no campo comercial, a competição das outras nações industrializadas logo transforma a balança comercial dos EUA em um permanente registro de perda de reservas. Coelho, Jaime Cesar. Economia, Poder E Influência Externa. O Banco Mundial E Os Anos de Ajuste Na América Latina. São Paulo: Editora Unesp, 2012: 145.
} 
também sofriam com o aumento dos preços da matriz energética, e que ao buscarem uma saída para o seu endividamento, endividavam-se ainda mais. ${ }^{8} 0$ crédito oferecido pelos bancos internacionais estava ancorado a juros flutuantes, e contudo, a taxa de juros havia variado muitíssimo pouco ${ }^{9}$ desde a instauração do sistema de Bretton Woods. Todavia, com a desarticulação do sistema monetário internacional, a estabilidade das taxas de juros tornar-se-ia passado. ${ }^{10} \mathrm{Em}$ poucos anos, as dívidas financiadas a juros flutuantes se tornaram o centro das políticas de coordenação econômica aplicadas aos países do Terceiro Mundo, que ficaram conhecidos como Programas de Ajuste Estruturais, os PAEs. Esses créditos também serviram para financiar projetos econômicos em andamento nas ditaduras militares, e o período vivido na América Latina legou aos processos de reabertura política um quadro econômico difícil com a explosão da dívida externa, contraída especialmente nos anos 1970, dentre outros quadros sociais lastimáveis.

O processo de transição da política econômica internacional também alterou o papel das Instituições Financeiras Multilaterais, ${ }^{11}$ as IFMs; exigindo sua adaptação frente às novas demandas da cartilha neoliberal de abertura dos mercados. Com o aumento da dívida dos países do Terceiro Mundo, as IFMs passaram a exigir critérios específicos para a liberação de créditos conforme os países tornaram-se mais endividados já nos anos 1970.

Conforme as economias do centro dinâmico capitalista retomavam a cartilha liberal oficialmente com os anos 1980 e a elevação da taxa de juros norte-americanos, ${ }^{12}$ a tentativa de articulação autônoma dos países produtores de matérias primas foi sendo expressamente erodida com o estouro da dívida. Dentro deste ciclo de desestruturação econômica internacional o Banco Mundial e o FMI também passaram a prescrever em seus pacotes, cláusulas relacionadas ao meio ambiente.

Esse momento foi de grande importância para o reordenamento da economia, tanto do ponto de vista da relação entre os países no cenário internacional, quanto da absorção destas alterações no plano das economias nacionais. Segundo a Escola da Regulação

\footnotetext{
${ }^{8}$ Segundo a declaração da ONUDI emitida em 1979 foi devido a manutenção do poder de compra do Terceiro Mundo que puderam ser reduzidos os efeitos da recessão do norte ao longo da década de 1970. Segundo estimativas da então CEE, (Comunidade Econômica Europeia), teriam ocorrido somente no território da Comunidade, três milhões de desempregados a mais, além dos seis milhões, se os países do Terceiro Mundo não tivessem mantido as suas importações de produtos manufaturados, entretanto, a manutenção deste processo de absorção ocorreu mediante o endividamento crescente desses países, frente aos bancos dos países do Primeiro Mundo, com fundos reciclados da OPEP. Ladislau Dowbor. A Formação Do Terceiro Mundo. São Paulo: Brasiliense, 1997: 147.

9 'As taxas baixas, ou mesmo negativas de juros, que se haviam mantido durante muito tempo, não permitiram suspeitar a armadilha constituída pela cláusula de taxa variável de juros imposta pelos bancos privados. Ignacy Sachs. "Internacionalização Da Economia Ou Desenvolvimento Endógeno? Os Lances Da Crise No Brasil." Revista de Economia Política. São Paulo, 1984: 47.

${ }^{10}$ Os norte-americanos enfrentavam duplos déficits crescentes em suas balanças comerciais e de pagamentos, com o crescimento das economias europeias e japonesas recuperadas do pós-guerra e dos gastos militares concebidos durante a Guerra do Vietnã. A paridade dólar ouro alcançava o seu limite, e em 1968 os EUA romperam com o lastro ouro colocando o Sistema Monetário Internacional, em xeque, meses após o acordo de vinculação dos preços do barril de petróleo exportado pela OPEP à variação do dólar.

${ }^{11}$ São elas: O Fundo Monetário Internacional, o Banco Mundial e o GATT (atual OMC), três organismos dominantes na economia internacional surgida no pós-guerra e que permaneceram ativos com a liquidação do Sistema de Bretton Woods.

${ }^{12}$ Os autores Gérard Duménil e Dominique Levy classificam a súbita alta da taxa de juros norte-americana como o Golpe de 1979; uma ação unilateral e não criticada pelas instituições internacionais atuantes na economia da época. A elevação dos juros levou ao estouro da dívida do Terceiro Mundo. A guinada dos juros pôs fim às disputas entre modelos de desenvolvimento, por meio da imposição dos critérios vinculantes para a liberalização de crédito fornecido pelas IFMs. A manobra interna realizou o ajuste econômico de todos os países às necessidades da economia estadunidense. Segundo Conceição Tavares, a manobra dos EUA buscou ditar a nova divisão internacional do trabalho em benefício próprio através da imposição internacional de um ajuste recessivo a todas as economias, reafirmando o status de sua economia não apenas como dominante, mas como cêntrica. Para mais: Duménil, G., e Lévy. "O Neoliberalismo sob a hegemonia norteamericana." in A finança mundializada: raízes sōciais e políticas, configuração consequências. Traduzido por Rosa $\mathrm{M}^{a}$ Marques, Paulo Nakatani (São Paulo: Boitempo, 2005), 85-108.
} 
francesa, o Regime de Acumulação e o Modo de Regulação ${ }^{13}$ se ajustaram às necessidades da manutenção da acumulação capitalista, redistribuíram a política econômica e as instituições para a dinâmica das finanças liberalizadas. Esta realocação das finanças promoveu novas possibilidades de controle sobre as nações terceiro mundistas, propiciando uma escalada qualitativa na orientação e indução de suas economias nacionais.

Os primeiros programas de ajuste aprofundaram os problemas ambientais dos países exigindo dos mesmos o aumento da exportação de suas commodities em substituição de plantações de subsistência. A proposta da Reforma Agrária de Mercado ${ }^{14}$ criada pelo Banco Mundial foi uma concretização deste novo regime de controle. A deterioração das reservas naturais foi ampliada, assim como a situação das famílias encaminhadas para as periferias das cidades, alavancando a favelização ao redor dos países ajustados.

A expansão das favelas nas últimas décadas foi consequência direta dos planos de Reforma Agrária de Mercado. Esta é a conclusão a que chegou Mike Davis, onde aponta nos oito capítulos de seu livro Planeta Favela, a explosão das megafavelas ao redor do Terceiro Mundo, onde expressa a íntima relação mantida entre a expansão destas com as políticas instituídas pelos ajustes estruturais. Tudo isso através da irresponsável voracidade e total desrespeito com que parte da população e os recursos naturais foram tratados pelos 'mercados'. (DAVIS, 2006, p. 214)

Em qualquer país devedor, conforme destaca Mimar Pimple, o setor que mais recebeu recursos do Banco Mundial foi o agrícola. O Banco Mundial defendeu a substituição de diversas variedades de produtos alimentícios por monoculturas de sementes importadas, como é o caso do monocultivo de espécies como o eucalipto, uma das que recebem os maiores investimentos do Banco Mundial, que resultou na degradação atestada dos solos e diminuição do volume da água em vastas regiões indianas. ${ }^{15}$

Por sua vez, após dez anos da Conferência de Estocolmo em 1972, as Nações Unidas, em Assembleia Geral, propuseram uma avaliação das transformações ocorridas ao longo da década. Isto viabilizou a formação da Comissão Brundtland que iniciou seus trabalhos em 1983. Quatro anos mais tarde, a Comissão publicou o resultado em seu relatório intitulado Nosso Futuro Comum, onde a conjuntura de crise da divida dos países do Terceiro Mundo apareceu em destaque, em especial no terceiro capítulo. Diante das distorções de mercado, da perda de trocas, dos altos cuistos dos serviços da dívida e do aumentou da pobreza, o relatório recomenda as IFMs a incluírem em seus programas de ajuste parâmetros ambientais. ${ }^{16}$

\footnotetext{
${ }^{13}$ Tanto o Regime de Acumulação, quanto o Modo de Regulação são termos usados pela Escola da Regulação para determinar mudanças que atravessam o desenvolvimento capitalista ao longo dos anos. De forma sintética, o Regime de Acumulação é formado pelo conjunto das regularidades econômicas e sociais que garantem o processo de acumulação a longo prazo. O Modo de Regulação é o conjunto de procedimentos capazes de reproduzir as relações centrais do processo de acumulação que dão a sustentação e as garantias necessárias ao Regime de Acumulação em vigor, além de permitir a direção de um conjunto de decisões descentralizadas. O Modo de Regulação é a face que demonstra a incorporação do "conjunto de procedimentos" reprodutores e garantidores do Regime de Acumulação nos indivíduos e coletivamente. Em suma, o Modo de regulação é a concretização social e individual do Regime de Acumulação em vigor."

${ }^{14}$ Para mais: Rosset, Peter. "O bom, o mau e o feio: A política fundiária do Banco Mundial"in O Banco Mundial e a terra. Ofensiva e resistência na América Latina, África e Ásia, org. Mônica Dias Martins. São Paulo: Viramundo, 2004

${ }^{15}$ Mônica Dias Martins. O Banco Mundial E a Terra: Ofensiva E Resistência Na América Latina, África E Ásia. São Paulo: Viramundo, 2004.

16 'A espiral de pobreza e degradação ambiental é um desperdício de oportunidades e de recursos. Em particular, é um desperdício de recursos humanos. Estas ligações entre pobreza, desigualdade e degradação ambiental é um tema em destaque em nossa análise e recomendações. O que é necessário agora é uma nova era de crescimento econômico, crescimento que seja forte e ao mesmo tempo social e ambientalmente sustentável. ONU. Our Common Future, 1987:14.
} 
O Relatório aponta para a existência de distorções econômicas, mas não aponta a causas das mesmas. Responsabiliza a crise, mas não propõe a suspensão dos pagamentos de juros, ou a redefinição dos objetivos dos projetos financiados pelo BM no Terceiro Mundo. Como solução, propôs um novo ajuste capaz de introduzir o conceito de desenvolvimento sustentável nos países do sul.

De todos os seus treze capítulos, o foco principal do Relatório Brundtland esteve centrado na participação do Terceiro Mundo, ou seja, o relatório gravitava em torno dos problemas de uma região econômica específica, na forma como a pobreza gerava a degradação ambiental, e como isso deveria ser alterado através do suporte das IFMs a partir de um novo tipo de ajuste que passava a ser pregado. Nas páginas do Relatório os países industrializados são definidos como coadjuvantes, cabendo aos mesmos uma função cooperativa no processo de ajuste das economias do Terceiro Mundo. As transnacionais por sua vez, tem seu papel mencionado, no entanto, elas também não são o centro das atenções do relatório. A pobreza, mais uma vez, é a geradora de degradação ambiental, todavia, como essa pobreza foi gerada, a causa da sua ampliação, não uma foi questão elaborada pela comissão que trabalhou no relatório.

O crescimento populacional é elaborado como ingrediente gerador de depredação ambiental o qual necessita de medidas diretas de controle, ou seja, o ajustamento neomalthusiano do passado não foi inteiramente descartado. No terceiro capitulo do Relatório, onde é abordada economia internacional, ocorre uma correlação entre pobreza, agricultura de subsistência e degradação ambiental motivada pela crise da dívida. A pobreza é apontada como causa de degradação, por meio da agricultura de subsistência, motivada pela pobreza extrema. Em Nosso Futuro Comum foi declarado que houve nos países endividados um aumento da degradação pelo modelo de autoplantio. Não foram mencionados casos, regiões, ou países onde esta correlação tenha acontecido, assim como não foi mencionado no relatório a relação existente entre o autoplantio e a nutrição das famílias. ${ }^{17}$

Assim como o Relatório Meadows, o Relatório Brundtland não apontou a responsabilidade da degradação ambiental para a industrialização, nem para quais condições econômicas os países estavam inseridos. Por mais que a emissão per capita das nações do G7 seja de 3,8 toneladas métricas ao ano, e o restante das emissões per capita do mundo seja de 0,7 toneladas métricas no mesmo período (Cf. FOSTER, B. 2002). A novidade trazida pelo relatório Brundtland foi vincular a necessidade do controle populacional e de desenvolvimento econômico à preservação ambiental; tratava-se agora de criar os meios para por em prática tal vinculação.

Por tanto, após condicionar as economias à cartilha dos ajustes, os anos 1990 assistiram a ampliação do liberalismo das economias endividadas através da abertura de mercados e da titularização ${ }^{18}$ de suas dívidas.

Alia-se a esse conjunto de novos elementos a desestruturação do Bloco Soviético, que determinou o termino da Guerra Fria e juntamente o equilíbrio histórico que existiu ao

\footnotetext{
17 O declínio dos anos 1980 agravou a pressão sobre o ambiente de várias formas: As medidas de austeridade e as condições gerais de recessão trouxeram fortes quedas na renda per capita e o aumento do desemprego. (...) Isto obrigou mais pessoas a voltarem para a agricultura de subsistência, onde extraem pesadamente os recursos naturais de base e, portanto, degradam-na. Our Common Future, 1987:79

${ }_{18}$ Nesta ação toma-se crédito no mercado em troca da oferta de títulos da dívida. Este processo atraiu investidores institucionais, fundos, companhias de seguros, etc., que passaram a operar sobre uma economia desregulamentada, desintermediada e plenamente aberta ao capital financeiro, o que acarretou profundas alterações no funcionamento do próprio capital produtivo. Os países endividados tiveram acesso ao mercado financeiro por remunerarem seus papéis a altos juros pós-fixados, e transformaram-se ao loñgo dos anos 1990 em alvo de especulação financeira, passando a serem tratados como plataformas de valorização do mercado secundário de ações.
} 
longo do pós-guerra até o início dos anos 1990. O fim do bloco acarretou uma série de transformações no contexto histórico no transcorrer dos anos seguintes, com a reacomodação da sociedade capitalista. Assim, com o fim da Guerra Fria, as políticas hegemônicas ditadas pela economia de mercado passaram a operar sobre novos limites.

O modelo preconizado de ajuste produziu efeitos devastadores sobre o meio ambiente e as populações locais, pois a busca incessante por superávits da balança comercial, mais a desvalorização do câmbio para gerar competitividade externalizaram custos ecológicos e sociais que não foram levados em conta nesta reorganização do comércio internacional. As práticas liberais ajustaram a pauta dos problemas enfrentados pelo acumulo de décadas de dilapidação dos recursos naturais e consumo intensivo de matérias primas, ambos retirados do meio ambiente, através da implementação de mecanismos de flexibilização econômicos abrigados sob o edifício do Protocolo de Quioto.

A CNUMAD, Conferência das Nações Unidas para Meio Ambiente e Desenvolvimento, ocorrida em 1992 no Rio de Janeiro instituiu duas Declarações, redigiu uma Agenda de ações e instalou duas Convenções, dentre elas a Convenção Quadro das Nações Unidas sobre Mudanças Climáticas, CQNUMC. A Convenção do Clima, como também ficou conhecida, foi fruto direto dos trabalhos iniciados pelo IPCC, Painel Intergovernamental de Mudanças Climáticas, em 1988 e da publicação do seu primeiro relatório em 1990. A CQNUMC foi criada com o objetivo de operacionalizar um acordo que mitigasse e reduzisse as emissões de Gases responsáveis pelo Efeito Estufa originados pela atividade humana, ou no vocabulário utilizado pelo IPCC, de origem antrópica. O resultado direto das discussões articuladas pela Convenção do Clima foi a instauração do Protocolo de Quioto, um processo de negociação que começou em 1994 com a Conferência das Partes (COP) em Berlim, e terminou na cidade japonesa em 1997.

A Convenção do Clima inịiou seus trabalhos em maio de 1992 e adotou três princípios que passariam a orientar suas discussões, são eles: precaução, poluidor pagador e responsabilidades comuns, mas diferenciadas. ${ }^{19} 14$. Princípios estes que deram origem aos mecanismos de flexibilização econômico posteriormente criados.

Apesar de onerar os países ricos com os custos de redução de emissões como medida obrigatória, o Protocolo de Quioto manteve o paradigma na esfera teórica. Na prática, o paradigma das responsabilidades comuns mas diferenciadas incorporou-se a lógica da divisão internacional do trabalho, não criando uma zona de regulação entre países historicamente poluidores, e países ricos em recursos natùrais. O princípio posto em prática por meio dos mecanismos favoreceu a manutenção das distorções econômicas e sociais, tal qual existente na divisão internacional do comércio.

Os mecanismos de flexibilização tem o objetivo de auxiliar os países responsáveis pelas alterações climáticas - segundo as conclusões defendidas pelo IPCC - a cumprirem as metas auto definidas de redução de emissão de GEE. Assim, o Protocolo de Quioto introduz três mecanismos de flexibilização, todos de fundamento econômico: o Mecanismo da Implementação Conjunta, o Mecanismo de Desenvolvimento Limpo, e por fim, o mecanismo que assegura a execução dos anteriores, o Mecanismo do Comércio Internacional de Emissões, o qual também assegura a participação de empresas privadas.

A influência norte-americana foi determinante para a definição dos mecanismos do Protocolo. O enviado da casa branca, o então vice-presidente Al Gore, reiterou a

\footnotetext{
${ }^{19}$ Para mais: Salviatti, Ana Paula. "A Financeirização Do Meio Ambiente O Caso Do Mercado de Créditos de Carbono." Universidade de São Paulo, 2013. http://www.teses.ùsp.br/teses/disponiveis/8/8137/tde-12022014-122211/pt-br.php.
} 
necessidade que de fossem criados mecanismos de flexibilização que permitissem às partes emissoras comprarem suas reduções de outras partes do acordo. ${ }^{20}$

As metas de redução não foram determinadas por métodos científicos, foram estabelecidas politicamente por cada uma das partes aplicadas, ou seja, as metas acordadas pelos países não possuem um nexo científico que se refira as necessidades reais de redução de emissão. Dessa forma, o total de emissões realizadas em 1990 é o referencial de medidas que os países assumiram a fim de calcular os níveis de redução para a primeira fase do Protocolo de Quioto. Somente após alcançar 55\% das emissões totais de 1990 o Protocolo passou a vigorar, o que só foi possível com a ratificação do acordo pela Federação Russa em 2005.

A partir da divisão estabelecida entre as partes foi desenvolvido o Mecanismo de Desenvolvimento Limpo, um instrumento de natureza econômica que permite o estabelecimento de relações comerciais baseadas na troca de Certificados de Emissões (CERs), ou simplesmente, créditos de carbono entre as partes Anexo I e Não Anexo I. Os países pertencentes ao Anexo I que possuiriam capacidade de prover assistência financeira aos países presentes no Não Anexo I foram agrupados em um subconjunto, o Anexo II. Entre as suas obrigações dos países Anexo I estão a de fornecer recursos tecnológicos e financeiros às partes Não Anexo I, além de reduzirem duas emissões de GEE.

Segundo o Protocolo, as partes presentes no Anexo I que possuem tetos de emissões determinadas pelo acordo devem auxiliar as partes Não-Anexo I - que não possuem tetos de emissões - a implementar atividades de redução de emissões dos GEE . Nesta relação de ajuda mutua, créditos são emitidos com base nas reduções obtidas pelas atividades. As atividades, e ou projetos, que busquem se estabelecer dentro dos Mecanismos de Flexibilização devem transitar pela esfera burocrática desenvolvida pelo Conselho Executivo dos mecanismos com o intuito de verificar a validade das atividades perante o que ficou conhecido como Cláusula de Adicionalidade. Esta é atendida quando o projeto proposto reduz concretamente o nível de emissões através de sua implementação, essa diferença se estabelece pela comparação do cenário de emissões anterior ao cenário após a introdução do projeto. Somente depois da autorização do Conselho Executivo dos mecanismos é que são emitidos as Reduções Certificadas de Emissões, e as Unidades de Emissões Reduzidas.

O Mecanismo do Comércio Internacional de Emissões funciona somente entre as partes presentes no Anexo I. Nele são comercializadas unidades de créditos criados tanto pelo Mecanismo de Desenvolvimento Limpo, as CERs, quanto os créditos criados pelo Mecanismo de Implementação Conjunta, as ERUs. Através do mecanismo do comércio de emissões, as Partes do Anexo I podem adquirir créditos de carbono, a fim de regularizar seu estoque de emissões. Na prática ao adquirir as CERs os países passam a ter seus limites de emissões aumentados, pois diferentes da modalidade dos créditos emitidos entre as partes do Anexo I, as ERUs, os créditos obtidos com o MDL permitem um abatimento de responsabilidades parte por parte e em todo o conjunto do Anexo I.

Desta forma, os créditos mais comercializados dentro do Mercado de Emissões são os mesmos que envolvem países de economia dinâmica e os de economia induzida, ou seja, são os emitidos pelo Mecanismo de Desenvolvimento Limpo. Assim, sua participação no mercado financeiro e seu impacto na implementação dos projetos nos países não Anexo I são os mais relevantes.

${ }^{20}$ Lohmann, L. Mercados de Carbono: La neoliberalización del clima. Quito: Abya-Yala, 2012. 
O nível de èmissão de gases responsáveis pelo efeito estufa em 1990 atingiu a marca de 90 bilhões de toneladas. O Protocolo de Quioto defendeu uma redução total de 5,5\% das emissões correspondente às emissões do ano de 1990. Para a primeira fase do acordo a meta era a de atingir uma redução de aproximadamente $5 \%$ dos gases emitidos entre os anos de 2008 a 2012. Ou seja, uma redução de 4,5 bilhões de toneladas de gases poluentes na atmosfera, ou uma média anual de aproximadamente 1.125 bilhões de toneladas de gases poluentes a menos. Segundo dados publicados pelo Banco Mundial, "no início de setembro de 2012, o número total de CERs emitidas passaram 1.000 MtCO2", o correspondente a 1 milhão de toneladas de gases não emitidos comercializados pelo mecanismo de MDL, o que corresponde a um valor muito abaixo do necessário para alcançar a meta de redução de emissões.

Diante de tais dados, o Mercado de Emissões criado pelo Protocolo de Quioto possui uma participação de aproximadamente 0,02\% do montante de emissões necessárias para as reduções totais dos países Anexo I, que passa da casa do bilhão de toneladas, conforme exposto. Por tanto, perante a motivação pela qual foi desenvolvido o Protocolo, a redução das emissões frente a deterioração do meio ambiente acarretada pelo aquecimento global, as ações desenvolvidas pelo mesmo foram insuficientes para barrar, ou mesmo mitigar o progresso do aquecimento global.

Entretanto, o Protocolo de Quioto pode ter fracassado em sua meta de estabelecer uma redução das emissões de gases causadores do aquecimento global, porém, para o mercado financeiro, o mercado de emissões é um dos mais promissores ramos de investimentos para os próximos anos. As projeções

os analistas financeiros, como Louis Redshaw, do Banco Barclays Capital, em 2009 apontavam que o 'carbono seria o maior mercado de commodities e poderia tornar-se o maior mercado de todos', pois para se aproximarem das metas propostas por Quioto, o comércio de emissões precisaria expandir-se muito mais. Posto que o mercado de emissões possui uma demanda muito grande para suprir, como um ramo de investimentos financeiros de "futuro". ${ }^{21}$

Um capítulo a parte da análise de toda esta grande estrutura burocratica instituida pelas Nações Unidas são os projetos implementados dentro do MDL. ${ }^{22}$ Cita-se um deles: A Alemanha até 2050 assumiu o compromisso de diminuir suas emissões de CO2 em 95\%, mas apenas poderá cumprir seu compromisso se desmontar suas usinas termoelétricas de carvão linhito, o mais sujo e poluente de todos os combustíveis fósseis, ou adquirir créditos de carbono. ${ }^{23}$ A usina termoelétrica de Niederaußem, na Alemanha usa para sua produção de eletricidade o carvão de linhito, ao ano ela lança 30 milhões de toneladas de CO2 na atmosfera. A operadora da usina é o truste de energia elétrica RWE que intervêm na bolsa de valores para comprar CERs quando a usina ultrapassa o teto de emissões que possui. A RWE é responsável pelo investimento em projetos de MDL, um deles foi criado em Lusaka, no Zâmbia. A RWE precisa provar que o uso de seus fogareiros por famílias pobres de Lusaka reduz a emissão de CO2, para isso a empresa não os distribui gratuitamente, vendeos para garantir seu uso final. Os aparelhos foram instalados com GPS para que empregados da empresa possam fazer o controle do uso dos mesmos. Para receber o

\footnotetext{
${ }^{21}$ Em 2008, o Credit Suisse montou um negócio de 200 milhões de dólares amarrando vários projetos em diferentes fases de execução antes de se separarem para vender em mercados secundários. Lohmann, L. Mercados de Carbono: La neoliberalización del clima. Quito: Abya-Yala, 2012.

22 Para mais projetos: Salviatti, Ana Paula. "A Financeirização Do Meio Ambiente O Caso Do Mercado de Créditos de Carbono." Universidade de São Paulo, 2013. http://www.teses.usp.br/teses/disponiveis/8/8137/tde-12022014-122211/ptbr.php.

${ }_{23}$ Henk, M., e Schaefer, J. "O Lucrativo Negócio com o Ar Poluído."Revista GEO, Junho 29, 2011, 109.
} 
pagamento das parcelas dos fogareiros, a RWE criou um sistema de pagamento eletrônico especialmente para recebê-los, numa cidade onde mal há semáforos de transito em funcionamento.

As lenhas que alimentam os fogareiros também são de responsabilidade do truste, que as produz em uma das suas cem áreas de reflorestamento. Em suma, a RWE se dá a todo este trabalho para garantir CERs em sua cota de CO2. Ao longo de um ano, os fogareiros implementados pela RWE, na Zâmbia, economizaram 130 mil toneladas de CO2, quantidade que a usina de Niederaußem emite em um único dia. Em 2009, a RWE, a maior emissora da Europa adquiriu 44 milhões de CERs no mercado de carbono. Adquirir CERs é um investimento muito atrativo, pois demandam muito menos das empresas do que alterações em suas cadeias produtivas. Quando uma usina como a Niederaußem ultrapassa seu teto de emissões ela possui duas alternativas: ou reduz a potencia de seus geradores, ou compra créditos no mercado.

No texto, Mercados de Carbono: La neoliberalización del clima, de Larry Lohmann, ${ }^{24}$ é apontado como o mercado de emissões possui forte participação no mercado secundário de ações, na forma derivativos financeiros. Tal corelação tem em vista, segundo o autor, o fato de que os mercados estão em busca de liquidez financeira. Os créditos de carbono passam por uma longa cadeia de averiguação e efetivação até serem liberados para comercialização, mas mesmo assim, muitos projetos que estão ainda no processo de validação de créditos já estão sendo negociados no mercado futuro, o que os torna uma mercadoria sujeita a forte variação, haja vista que os mesmos podem não ser emitidos. Há também créditos que estão sendo comercializados no mercado futuro como créditos que virão a ser emitidos de projetos já avalizados pelo MDL, ou seja, tais ações geram sérios riscos nos mercados financeiros, conforme Michelle Chan, ${ }^{25}$ um possível colapso no valor daquilo que ela chamou de "carbono subprime" pode provocar um forte impacto não só sobre o clima, mas também sobre o sistema econômico.

O comércio de carbono, por tanto, surge dentro de um contexto muito específico. A configuração dos mecanismos de flexibilização criados em Quioto corresponde às distorções descritas ao longo das páginas anteriores. O Protocolo de Quioto é fruto da mesma divisão internacional do trabalho responsável pelo consumo e uso dos recursos naturais tal qual se apresentam na atualidade. Desta feita, medidas reguladoras que estabeleçam como saídas ferramentas pró-mercado como os instrumentos de flexibilização do Protocolo reproduzem e acentuam ainda mais a série de distorções econômicas que definiram a subordinação dos países ajustados às economias capitalistas dinâmicas.

Os acordos em torno da degradação ambiental e do desenvolvimento voltado aos países ajustados foram estruturados nos anos 1990, no esteio do novo padrão econômico adotado, onde as agendas do capital financeiro passaram a ser internalizadas pelas agendas políticas das Nações Unidas conforme o liberalismo econômico reestruturava à sua maneira a economia internacional. Dessa forma, o conjunto de políticas elaboradas para a preservação ambiental que foram adotadas pelos países ajustados são fruto da lógica implementada pelos Programas Ajuste Estrutural.

Imperativo pontuar que a construção do expediente sobre a dilapidação ambiental e o desenvolvimento dos países terceiro mundistas desde o início dos debates feitos pela Organização das Nações Unidas reverberou diretamente as condições encontradas na

\footnotetext{
${ }^{24}$ Lohmann, L. Mercados de Carbono: La neoliberalización del clima. Quito: Abya-Yala, 2012.

${ }^{25}$ Michelle Chan. Subprime Carbon? Rethinking the World's Largest New Derivatives Market. Washington: Friends of the Earth, 2009. http://www.foe.org/subprime-carbon-Testimony.
} 
política econômica internacional. Construiu-se de forma unívoca a compreensão que manteve ligada tanto a preservação e o acesso às fontes de recursos naturais e matérias primas, quanto o desenvolvimento das nações ajustadas ao mesmo conjunto de soluções políticas. Tudo isso feito sobre a racionalização lógica da liberalização dos mercados, que resultou em retrocessos tanto para as economias que sofreram a indução de suas políticas nacionais, quanto para o meio ambiente que aprofundou a condição de degradação em que se encontra.

Como exemplos desta expansão do processo de mercantilização ${ }^{26}$ instalado com a liberalização econômica apontam-se as tentativas de expandir o crédito através da "matematização" e da privatização de uma variedade sem precedentes de incertezas nos mercados de derivativos, a criação dos direitos de propriedade intelectual, ${ }^{27}$ a conversão dos recursos naturais em itens prestadores de serviços, conforme proposto textualmente na Declaração de Capital Natural da PNUMA, ${ }^{28}$ a transformação dos serviços de saúde, e até mesmo de espécies biológicas, em produtos quantificáveis e comercializáveis. Assim, as políticas internacionais favoráveis ao meio ambiente não fugiram à lógica das finanças e deram vasão à sua mercantilização.

Em Economia, Poder e Influência Externa, Jaime Coelho, defende a interpretação de que os programas de ajuste estruturais representaram o mecanismo de 'correia de transmissão' dos interesses de países industrializados diante das nações endividadas. Dessa forma as políticas internacionais de meio ambiente, elaboradas e aplicadas ao longo dos anos 1990, concretizadas no documento final do Protocolo de Quioto, funcionaram como um elo privilegiado de transmissão de interesses que constitui a moderna divisão internacional do trabalho, representada na economia mundial. Trata-se da disputa pelo excedente, do controle da acumulação e da distribuição de riqueza, no qual as fontes de recursos naturais e a autonomia dos países detentores dos mesmos possuem um lugar de destaque.

\footnotetext{
${ }^{26}$ Aqui entendido como um processo que busca criar novas mercadorias.

27 Teixeira, R. "Dependência, Desenvolvimento e Dominância Financeira: a economia brasileira e o capitalismo mundial."Universidade de São Paulo, 2007.

${ }^{28} \mathrm{O}$ aumento da pressão sobre os recursos naturais ao longo da década passada reverteu a tendencia de queda nós preços dos recursos naturais em 100 anos. A declinante quantidade e qualidade da água, a perda de espécies, e a degradação dos ecossistemas não são apenas material para financiamento de projetos, mas também a outras classes de ativos, como renda fixa, ações, diferentes tipos de seguros e finança corporativa. A Declaração de Capital Natural constrói a compreensão dos riscos do capital natural inerente a todas as classes de ativos relevantes, permitindo as instituições financeiras a informar e fortalecer seus modelos de risco de crédito. United Nations Environment Programme. "The Natural Capital Declaration. "A Commitment by Financial Institutions to Mainstream Natural Capital in Financial Products and in Accounting, Disclosure and Reporting Frameworks." Finance Initiative. UNEP., 2012.
} http://www.unepfi.org/fileadmin/documents/ncd_booklet.pdf. 